\title{
CLINICAL IMPLICATIONS OF p53 ALTERATIONS IN ORAL CANCER PROGRESSION: A REVIEW FROM INDIA
}

\author{
K.R. Patel', B.N. Vajaria', R.D. Singh ${ }^{1}$, R. Begum ${ }^{2}$, P.S. Patel ${ }^{1,}$ * \\ ${ }^{1}$ Biochemistry Research Division, Gujarat Cancer \& Research Institute, Asarwa, \\ Ahmedabad 380016, Gujarat, India \\ ${ }^{2}$ Department of Biochemistry, M.S. University of Baroda, Vadodara 390002, Gujarat, India
}

\begin{abstract}
p53 plays a central role in prevention of normal cell from the development of the malignant phenotype. Somatic alterations (mutations, loss of heterozygosity, deletions) in p53 are a hallmark of most human cancers and cause defects in normal p53 function. However, in the tumors harboring wild-type $p 53$, there are alterations in the regulation of the p53. Thus, understanding why p53 is unable to perform its role as a tumor suppressor in these wild-type tumors is very crucial. Germ-line polymorphisms in $p 53$ are also anticipated to cause measurable disturbance in p53 function. Over-expression as well as polymorphic variants of MDM2 might have effects on cancer development. In addition, degradation of p53 by E6 protein of high risk human papillomavirus is also suggested as one of the mechanisms which attenuate p53 responses in oral carcinogenesis. p53 has also been demonstrated to mediate cellular responses upon various DNA damaging cancer therapies, importantly, apoptosis. These responses have been implicated in an individual's ability to respond to these cancer therapies. Thus, exploring mechanisms by which normal function of p53 is affected in the comprehensive way in oral cancer might aid in the identification of tumor characteristics, prognosis and thus in the development of a new approach to treat the oral cancer.
\end{abstract}

Key Words: p53 mutations, p53 polymorphisms, MDM2, HPV, oral cancer.

One third world burden of oral cancer cases is reported from India [1]. Though, tobacco usage is an established risk factor for oral cancer development, the role of high-risk human papillomavirus (HR-HPV) in etiopathogenesis of oral cancer has come up in most of the epidemiological studies [2, 3]. It has been reported that the clinico-pathological and molecular pathological profile of tobacco-smoking and alcohol associated oral cancers in the western countries were different from tobacco-chewing associated oral cancers, mainly in the Indian subcontinent [4]. Further, human papillomavirus (HPV) positive oral cancer patients show different molecular properties and are considered as a distinct clinical-pathological entity with different outcomes and response to treatment as compared to HPV negative oral cancer patients [5]. Beside the above mentioned exogenous risk factors, inherited genetic factors also make an individual susceptible to oral cancer development.

Cancer develops through the accumulation of genetic alterations in genes involved in cell cycle regulation, angiogenesis, apoptosis, DNA repair, etc [6]. Oral cancer occurs as a consequence of various molecular events that collectively develop from an exposure to carcinogens present in the environment and an individual's genetic susceptibility [7]. This leads to damage of individual genes or portions of genetic materials. Most of these alterations involve activation of proto-oncogenes and/or inactivation of tumor

Submitted: August 03, 2017.
$\begin{array}{ll}{ }^{\star} \text { Correspondence: } & \text { E-mail: prabhudas_p@hotmail.com } \\ & \text { Fax: 079-2268 } 5490\end{array}$

Abbreviations used: GOF - gain of function; HPV - human papillomavirus; HR-HPV - high-risk human papillomavirus; LOH - loss of heterozygosity; LR-HPV - low risk human papillomavirus; MDM2 - mouse double minute 2. suppressor genes. Many investigators have evaluated a range of molecular markers involved in the oral carcinogenesis, including molecules involved in the cell cycle regulation, DNA repair, apoptosis, angiogenesis and extracellular matrix degradation. However, the existing data about the role of molecular markers in oral cancer development are still unclear and inconclusive.

$p 53$, a tumor suppressor gene has come up to the forefront of cancer research because it is commonly mutated in human cancer. Curiosity in the p53 has generated a large amount of information regarding the complexity of its function and regulation in carcinogenesis.

The $p 53$ gene is located on the short arm of chromosome 17 with 11 exons, of which 10 are coding. The p53 protein is comprised of 393 amino acids and divided into five domains with each domain having a different structure and function. The most important role of p53 is to integrate signals emerging from a wide range of cellular stresses, including stresses due to environmental carcinogen exposure. p53 induces adaptive and protective cellular responses through triggering the transcription of specific genes which prevent erroneous cell proliferation, by inducing growth arrest at the stage of cell cycle followed by DNA damage or apoptosis, if the damage is not repairable. Thus, it preserves the integrity of the genome (Fig. 1). These functions of p53 make this protein as the "guardian of the genome" [8].

Disturbance in the p53 is an almost frequent event in cancerous tumors. Somatic mutations in $p 53$ with the aim of absence or dysfunction in p53 protein is one of the most universal mechanisms by which the p53 pathway is damaged during carcinogenesis. These mutations are mainly single base substitutions that result in amino acid substitution [9]. Importantly, 


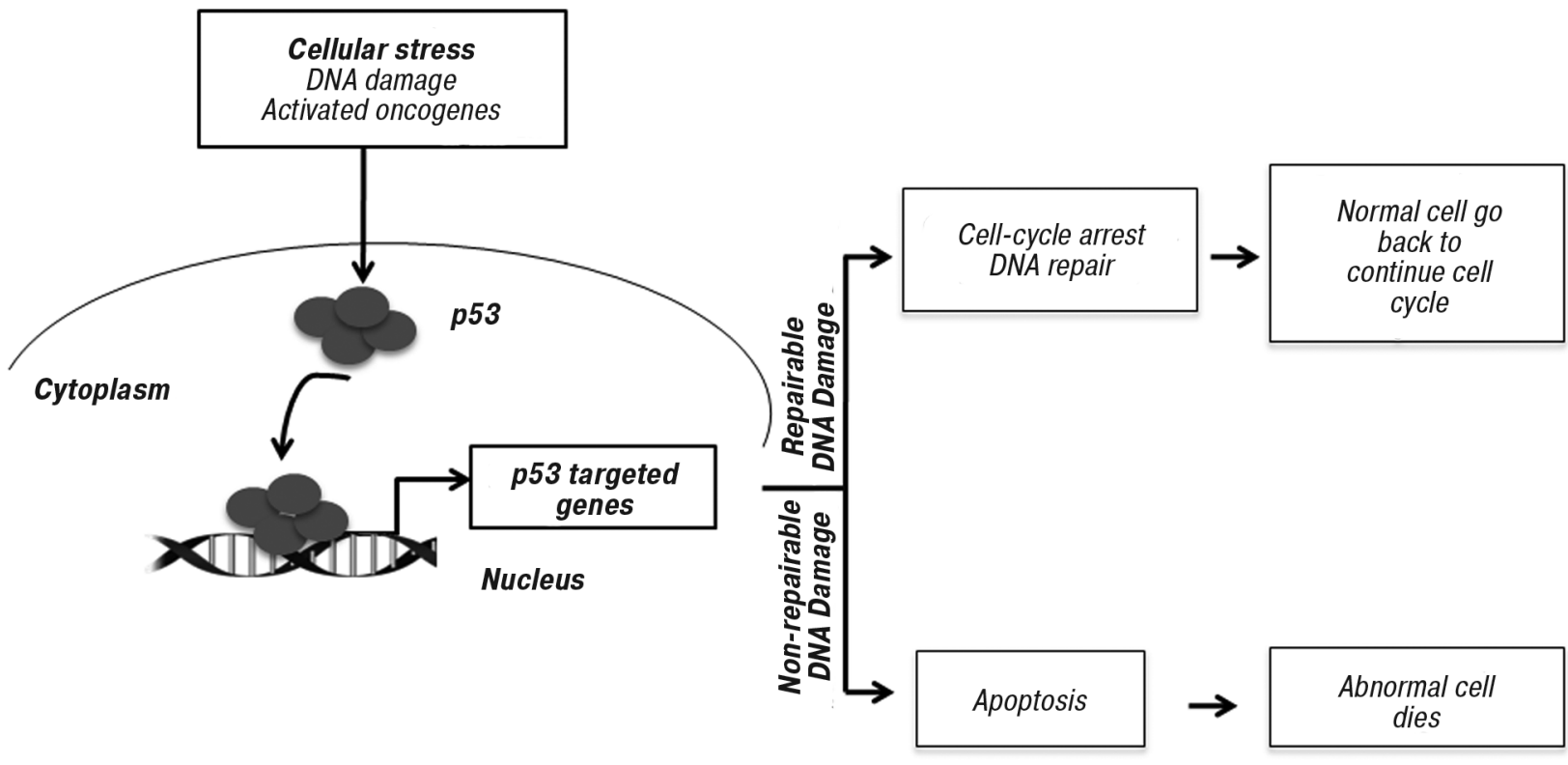

Fig. 1. Tumor suppressor gene $p 53$; guardian of the genome these missense mutations in p53 gene are usually followed by loss of heterozygosity ( $\mathrm{LOH})$, suggesting that there is a selective advantage conferred by losing the remaining wild-type $p 53$, even after one allele has been mutated [10]. It was also reported that p53 LOH is a critical prerequisite for missense mutant p53 stabilization and gain of function (GOF) in vivo [11]. Further, it was also observed that deletion at 17p13.1 locus of TP53 gene was among the most common alterations found in primary solid tumors [12]. Unlike these somatic alterations, the majority of polymorphisms in the $p 53$ gene are also expected to be associated with cancer risk by compromising the normal activities of p53 [9]. The levels of p53 in normal cell are tightly controlled. Under normal conditions, mouse double minute 2 (MDM2), a key negative regulator of p53 binds to its transactivation domain and ubiquitylates, targeting it for degradation [13]. Since p53 transcriptionally activates MDM2, the expression levels of p53 and MDM2 are balanced through a feedback negative loop. This balance is altered in stresses such as DNA damage which leads to increased p53 levels [14]. Underlying this crucial role of MDM2 in the control of p53 functions suggested that polymorphisms in the MDM2 gene may be responsible for probable alterations in p53 functions. Moreover, degradation of p53 by E6 protein of HR-HPV is also one of the mechanism by which normal function of p53 is altered in HPV associated oral carcinogenesis [3]. Together, all of above mentioned mechanisms leads to alterations in p53 responses in cancer cell (Fig. 2). Thus, exploring mechanisms by which p53 responses are affected in the comprehensive way might aid in the identification of tumor characteristics, prognosis and thus in the development of a new approach to treat cancer. The present review aims to summarize advances in p53 research, especially in oral cancer with special emphasis on somatic mutations and germ-line polymorphisms in the $p 53$ gene.

\section{p53 MUTATIONS IN ORAL CANCER}

Approximately, 10\% (hematopoietic malignancies) to $50-70 \%$ of all other human cancers are found to have somatic mutations in the p53 gene [15]. The frequency of $p 53$ mutations also varies according to the tumor type [16]. Wide variations in the frequency of p53 mutations have been reported between different studies of the same tumor type, probably reflecting methodological and geographic differences [17]. Also the frequency of p53 mutations has been also observed to vary between groups which differ in ethnicity or nationality for some cancer types [18]. This may be due to specific carcinogen exposure or inherited features in those populations.

Cancer-associated mutations in p53 are primarily missense substitutions non-randomly distributed along the molecule, particularly in the central DNA binding domain [15]. These single amino acid changes affect

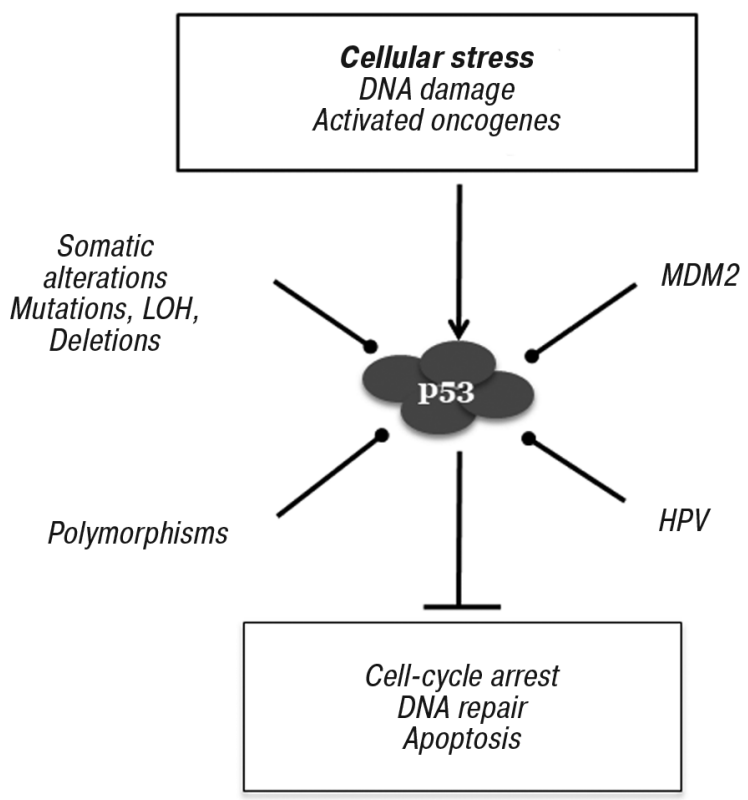

Fig. 2. Mechanisms that lead to alteration in p53 responses 
transcriptional activity of p53 to various degrees. However, all mutations do not have an equal deleterious effect on p53 function, and some missense mutants may even acquire new functions [15, 19]. Different mutations have different effect on the function of the p53 protein. Evidences also have suggested that mutant p53 not only loses its tumor suppressive function, but also has dominant negative effect on the remaining wildtype allele [20]. Moreover, mutant p53 has also ability to transcriptionally activate genes involved in increased proliferation, inhibition of apoptosis, limitless replication, angiogenesis, invasion and metastasis, etc [10, 16]. Thus, mutant p53 promotes tumorigenesis through many different aspects of oncogenetic processes and hence, mutant p53 may play a central role in tumorigenesis, almost in all the "hallmarks of cancer" (Fig. 3 ). However, how different forms of mutant p53 affect tumorigenesis is still unclear.

\section{Increased}

proliferation

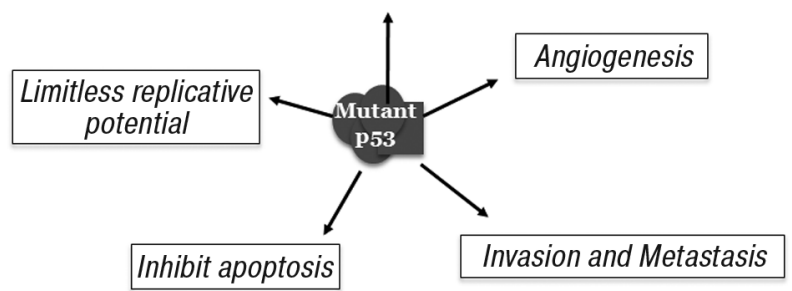

Fig. 3. Mutant $p 53$ contributes to tumorigenesis

In head and neck tumors, the prevalence of $p 53 \mathrm{mu}$ tation varies from $30 \%$ to $70 \%$, depending on the methodologies used to assess $p 53$ mutations, types of the tumor material and heterogeneity of the tumor sites examined [18]. The other reason for these wide variations could be different levels of exposure to risk factors like, tobacco and alcohol in the studied populations as mentioned earlier. There are reports on p53 mutation profile in oral cancers from various regions of India also. Reports from Southern India showed $p 53$ mutations in $17 \%$ and $21 \%$ of oral cancer cases [21, 22]. Studies from Western and Northern region also reported that $17 \%$ of oral cancer patients harbor p53 mutations [23, 24]. In contrast, no p53 mutations were reported in the study from Orissa, the Eastern region of India [25].

It was suggested that the incidence of $p 53$ mutations in oral cancer patients was associated with a history of tobacco use [26, 27]. However, there are the studies which have reported no association of $p 53$ mutation with smoking [28]. Further, it was observed that the p53 mutation frequency in betel quid/tobacco-associated Asian oral cancer (15\%) was significantly different from worldwide oral cancers, i.e. 46\% [29]. There are reports which suggested that $p 53$ mutation pattern also differ in group of having different type of tobacco habits [30, 31]. Recently, we observed different type of base pair changes and the multiple mutations in $p 53$ gene in oral cancer patients which suggest DNA insults by several different carcinogens which are present in smokeless tobacco. Our results on $p 53$ mutation spectrum strongly support the notion that ethnic/geographic and differences in tobacco consuming habits are the major cause of variations in the $p 53$ mutations [32]. Thus, the $p 53$ mutational pattern has been recommended to be a clinically appropriate "molecular sensor" for genotoxic exposure to carcinogens present in the environment and endogenous mutagens [33].

\section{p53 POLYMORPHISMS IN ORAL CANCER}

Several sequence variations are present in the p53 gene. Most of these variations are intronic and have no cancer related biological consequences [9]. The International Agency for Research on Cancer (IARC) TP53 mutation database lists 29 common polymorphisms in the non-coding region of TP53 [34]. However, of which, two intronic polymorphisms in $p 53$ gene; 16 bp duplication in intron 3 (rs17878362) and G>A transition in intron 6 ( $r$ 1625895) have been suggested to affect the levels of $p 53$ gene expression as well as its functions [35]. Also, it is important to mention that the functional role of these two intronic polymorphisms of $p 53$ in cancer risk remains uncertain which is discussed in detail in our previous article [36]. Very few studies have reported the association between these two intronic polymorphisms and oral cancer risk. Galli et al. [37] have reported that intron 3 polymorphism was associated with increased oral cancer risk. However, the same study also suggested that intron 6 polymorphism was associated with reduced oral cancer risk in Italian population. From India, only one study has analyzed the association between these two polymorphisms and oral cancer risk. The results revealed no association between intron 3 polymorphism and oral cancer risk; however, a variant allele at intron 6 was protective for oral cancer development in population from east region of India [38]. However, in our study, none of this intronic polymorphism was significantly associated with oral cancer risk in population from West India [36].

Of the 19 exonic polymorphisms, 11 polymorphisms in p53 are non-synonymous, resulting in an amino-acid change and only four of these have been validated. Out of these, there are sufficient molecular evidences for two polymorphisms (Pro47Ser and Arg72Pro) suggesting their role in functional change of the p53 protein. The rest two polymorphisms (V217M and G360A) have not been associated with an altered cancer risk till date [9]. The codon 47 polymorphism resulting in proline to serine substitution is rare whereas arginine to proline substitution in codon 72 is common $[39,40]$. It was reported that Arg to Pro polymorphism at codon 72 in exon 4 affects the structure of p53 protein and its biochemical and biological activities [41]. In our previous article, we have discussed various studies, which have reported how this polymorphism affects various important functions of $p 53$ such as cell cycle regulation, apoptosis, transcriptional trans-activation capacity and senescence (Fig. 4) [36]. 


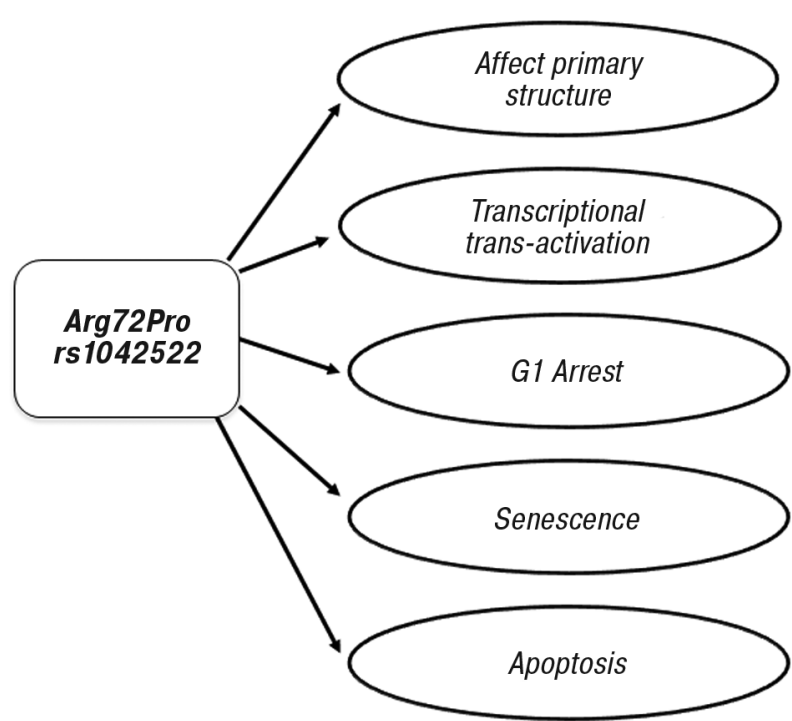

Fig. 4. $p 53$ Arg72Pro polymorphism and its influence on $\mathrm{p} 53$ functions

It was also observed that the p53 protein harboring Arg allele was more susceptible to degradation by HPV E6 protein and had a significantly higher frequency of $p 53$ mutations $[42,43]$. Moreover, it was also reported that there is a tissue specific influence of Arg72Pro polymorphism on apoptosis [44]. Recently, Hu et al. [45] observed that Pro form of $p 53$ gene has significantly higher levels of BPDE induced apoptotic index compared to Arg form in primary lymphocytes. Moreover, the Arg form of $p 53$ gene was associated with poor apoptosis in head and neck tumors [46]. Such tissue specific function of this polymorphism may explain why most of the epidemiological studies remain inconclusive.

We have discussed various studies from India in our previous research article and observed that no significant association of Arg72Pro polymorphism with oral cancer risk was observed in most of studies [36]. Further, it was suggested that the association of Arg72Pro polymorphism with cancer risk was modulated by ethnicity, allelic frequency, histological and anatomical sites of tumors [47]. However, recent meta-analysis of Arg72Pro polymorphism of $p 53$ suggests no association of this polymorphism with oral cancer risk as even after stratifying by ethnicity [48]. Also, a recent meta-analysis by Mandal et al. [49] suggested that Arg72Pro polymorphism may not be an independent risk factor for cancer in Indian population. However, still to provide conclusive results, all the intronic and exonic polymorphisms should be considered simultaneously. Our recent study considering all these three polymorphisms simultaneously suggested that carriers of absence of $16 \mathrm{bp}$ duplication allele at intron 3, proline allele at exon 4 and $\mathrm{G}$ allele at intron 6 were protected from oral cancer development [36].

p53 can also be inactivated by alternative mechanisms other than somatic mutations and germ-line polymorphisms. Here we summarize two important events that alternatively inactivate p53: (1) Polymorphisms in MDM2 gene and (2) HPV infections.

\section{MDM2 AND ITS ASSOCIATION WITH p53}

Because MDM2 is a key negative regulator of p53 activity, over-expression of MDM2 inhibits the p53 responses. Hence, in order to activate p53, eukaryotic cells have to develop mechanisms to block this negative feedback regulation in response to variety of stress. These mechanisms include posttranslational modification of either p53 or MDM2 such as acetylation, phosphorylation and protein-protein interaction. However, cancers often take advantages of this feedback loop to promote their growth as various tumors express high levels of MDM2 through distinct mechanisms without p53 mutations [50]. It has been reported that MDM2 transgenic mice expressing higher levels of MDM2 in various tissues, develop spontaneous tumors compared to non-transgenic mice [13]. Thus, over-expression of MDM2 has an effect on tumor susceptibility in mice. In fact, reports suggest that over-expression of MDM2 commonly occurs in oral cancer [51, 52]. Recently, novel MDM2 splice variants were identified in oral cancer at a high frequency and were found to be significantly associated with oral cancer development [53]. Taken together, MDM2 may play a significant role in oral carcinogenesis. Therefore, it is biologically plausible that functional genetic variants in the MDM2 gene may have an effect on cancer development in the general population.

It has been reported that one intronic polymorphism ( $T>G$ in the Sp1-binding site within the intronic promoter region, rs2279744) of MDM2 may increase the affinity of the Sp1 transcriptional factor, which results in higher MDM2 mRNA and protein levels. Thus, the presence of this polymorphism may attenuate the p53 responses, hence increasing cancer susceptibility $[9,54]$. There are very few studies, which have investigated the association of this MDM2 polymorphism with oral cancer risk. Two risk association studies highlighted that MDM2 polymorphism did not alter the risk of oral cancer, but may influence the age of disease onset [13,55]. A study on MDM2 polymorphism and oral cancer risk from India suggested that this polymorphism could not modify the risk of oral cancer independently [56]. However, authors suggested that this polymorphism may modulate cancer risk in combination with $p 53$ and $p 73$ polymorphisms. More interestingly, a recent meta-analysis by Zhuo et al. [57] also suggested that homozygote GG alleles of MDM2 SNP309 may be a low-penetrant risk factor for $\mathrm{HNC}$, and $\mathrm{G}$ allele may confer nasopharyngeal cancer susceptibility.

\section{HPV INFECTION AND ITS ASSOCIATION WITH p53 PROTEIN}

The participation of HPV in oral carcinogenesis was first proposed by Syrjanen et al. in 1983 [58]. HPVs have been divided into two groups: (1) High Risk HPV (HR-HPV) and (2) Low Risk (LR-HPV). HR$\mathrm{HPVs}$ are mainly associated with potentially malignant lesions, e.g. HPV 16 and 18, whereas LR-HPVs are more commonly associated with benign diseases, e.g. 
HPV 6 and 11 [3]. The molecular mechanisms by which HPVs disrupt key cellular elements responsible for cell cycle regulation and apoptosis have been identified. HPV E6 oncoprotein degrades p53 protein. Thus, cells that contain damaged DNA enter aberrantly into mitosis, sustain proliferative ability and may eventually contribute to the propagation of structural chromosomal abnormalities in HR-HPV associated cancer [59].

Various investigators have reported prevalence of HPV infection in oral cancer worldwide [60-63]. However, results show large variations from low prevalence to high prevalence. Also several reports from Bangladesh, various countries from central Europe and Latin America did not find HPV infection in oral cancer [64-67]. There are large regional and time trend variations in prevalence rates of HPV in oral cancers [68]. Recent reviews suggest that separation of oral carcinoma from the heterogeneous group of head and neck carcinomas is very essential to gain valid results of HPV prevalence in oral cancers [60,62].

Prevalence of HR-HPV type 16 and 18 infections in oral cancers varies widely across the different geographical regions of India. Prevalence of HPV 16 infection is reported to vary from $6 \%$ to $45.8 \%$, whereas HPV 18 infection from $0 \%$ to $54.2 \%$ of oral cancers from India which was reviewed in our previous article [69]. HPV positive oral cancers are highest from Southern India, while the Western part of the country (Mumbai) exhibits low HPV positive oral cancers [69]. Recently, we have reported absence of HPV16 and 18 infections in oral cancer patients in population from Gujarat, West India [69].

\section{p53 ALTERATIONS \\ AND CLINICOPATHOLOGICAL CHARACTERISTICS}

The prognostic value of p53 in oral cancer has long been debated. Contradictory results have been published about the presence or absence of $p 53$ gene mutations and the outcome in oral cancer. Yamazaki et al. [70] suggested that mutations within the DNA binding domain of $p 53$ could be important prognostic factors for locoregional failure, lymph node metastasis and the occurrence of subsequent distant metastasis in oral cancers. It was also reported that a dominant negative mutation in $p 53$ may be a good predictor of early recurrence in oral cancer patients [71]. However, Tsurusako et al. [72] suggested that p53 mutations may not be strongly involved in the development of well differentiated tongue cancers. In a recent study, faster tumor growth, higher frequency of metastasis in cervical lymph node and shorter survival was observed in mice injected with cells harboring disruptive p53 mutations as compared to mice injected with cells lacking these mutations [73]. Also the results of our study strongly suggest that evaluation of p53 mutation status could be useful for predicting loco-regional recurrence at early stage among oral cancer patients. Further, detection of p53 mutation in apparently normal adjacent mucosa along with mutation with tumor tissues should be done for prognostication. p53 mutations also affect the survival rate as cases with truncating and transcriptionally non-active p53 mutations had poor disease free as well as overall survival [32]. However, the results of a recent meta-analysis by Tandon et al. [74] highlights that the existing data regarding the prognostic importance of $p 53$ are indecisive and there is a great heterogeneity observed in various studies.

It was also observed that MDM2 GG genotype and p53 mutations were associated with poor diseasefree survival in both early and lymph node positive advanced stage oral cancer patients [75]. In a multicenteric study by the IARC, an inverse association was observed between the incidence of $p 53$ mutations and HPV 16 positivity in oral cancer patients [76]. However, Kozomara et al. [77] suggested that p53 mutations in combination with HPV infections were associated with an increased risk of recurrence and worse prognosis in oral cancer patients. The HPV positive oral cancer had improved outcome [5, 63, 78]. Further, it was suggested that inactivation of p53 protein by HPV is not as harmful as the mutations induced by other carcinogens present in environment [2]. It may be because the wild type p53, which escape HPV mediated degradation, might trigger cellular apoptosis following cancer therapy.

\section{ASSOCIATION OF p53 ALTERATIONS WITH TREATMENT OUTCOME}

The most used line of treatment for oral cancers is surgery followed by radiotherapy and/or chemotherapy. Multitasking of p53 is essential for the suppression of tumor, as well as for activating the cellular responses to DNA damage inducing cancer therapies such as radiotherapy and chemotherapy [79]. It was reported that $p 53$ mutations in the DNA binding domain might be useful to predict the radioresistance in oral cancer patients [80]. Yasumoto et al. [81] suggested that the X-ray sensitivity of wild type $p 53$ cells may come from the expression of genes involved in apoptosis. Moreover, Tu et al. [82] suggested that both MDM2 T>G and p53 Arg72Pro polymorphisms could be useful for evaluating the outcome of advanced oral cancers treated with adjuvant radiation.

Interest in cisplatin-based neoadjuvant chemotherapy has recently emerged due to its survival benefits in patients with locally advanced oral cancer. Recently, Perrone et al. [83] suggested that the mutant p53 proteins with loss of function may predict a significant low pathologic complete remission rate and suboptimal response to cisplatinbased neoadjuvant chemotherapy in patients with oral cancer. Moreover, sensitivity to cisplatin was positively associated with the presence of functional p53 in 60 human tumor cell lines of a National Cancer Institute ( $\mathrm{NCl}$ ) panel [84]. In addition, tumor cell lines that harbor non-functional p53 were more resistant to cisplatin than those harboring functional p53, but can be sensitized when reconstituted with wild-type p53 [85]. However, the association of p53 status and 
cisplatin cytotoxicity depends on several other factors, like types of tumor cells, the presence of other genetic alterations etc. Further studies on such genetic alterations are required to determine the role of p53 in cisplatin cytotoxicity. Proteins that are involved in p53 pathways can also modulate p53 responses as mentioned above and thus, cisplatin cytotoxicity. It was suggested that MDM2 overexpression affects the p53 responses under stress conditions, even in the presence of wild type p53 and results in to faster cancer progression and resistance to therapy in some tumor types [53]. Further, emerging evidence in the literature recommend that p53 (Arg72Pro) and MDM2 ( $>\mathrm{G})$ and p53 protein degradation by HR-HPV as mentioned earlier could also determine the patients' ability to induce p53 responses to DNA damaging therapies [79].

Various studies have confirmed that Arg72Pro polymorphism can affect the levels of apoptosis both in the context of wild type p53 and mutant p53. Wild type p53 in combination with Arg allele mediates the p53 dependent apoptotic response more efficiently. Interestingly, with mutant p53 protein, Pro allele could be associated with higher levels of apoptosis (Fig. 5) [79]. Also this observation was supported by two studies on advanced head and neck squamous cell carcinomas that received cisplatin based chemoradiotherapy. The authors observed that patients harboring wild type p53 and Arg genotype as well as patients with mutant p53 in combination with Pro genotypes had better response rates as well as overall and progression-free survival [79]. Further studies are recommended to understand these differences in the apoptotic response of p53 [86].

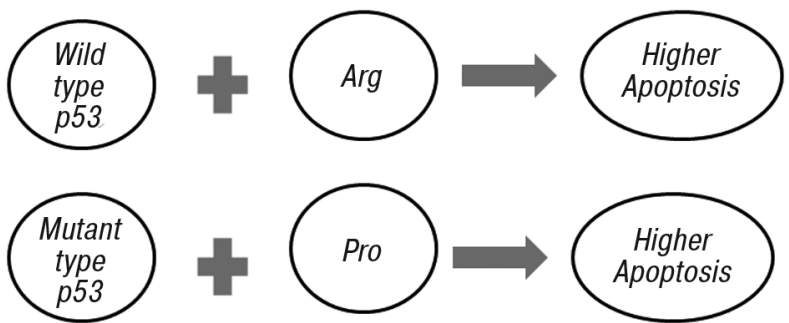

Fig. 5. p53 Arg72Pro polymorphism and mutation in combination affect its apoptotic function

Hence, knowledge of $p 53$ somatic mutational status as well as the $p 53$ Arg72Pro genotype of the patient could help to delineate the patient populations that will respond to chemo-radiotherapies. However, the utility of $p 53$ Arg72Pro polymorphism as a predictive biomarker requires mutational analysis of $p 53$. A recent study suggests that MDM2 T>G polymorphism is an independent predictive biomarker for selection of patients who respond to radical chemo-radiotherapy [87]. Together, these studies of $p 53$ Arg72Pro and $M D M 2 T>G$ indicated that high frequency SNPs in p53 pathway genes could affect the activity of p53 in cancer cells and thereby influences therapeutic responses.

In addition to this, p53-MDM2 pathway presents many molecular targets for screening small molecules as potential therapies for tumors harbouring wild type p53. A number of new small molecules have been identified to target MDM2 in the past decades and have entered Phase I clinical trials [50]. One of these compounds, Nutlin-3, binds with MDM2, dislodges p53 from MDM2 inducing p53-mediated apoptosis in leukemias, and is under phase I clinical trial for leukemia and solid tumors [88]. Further, a small molecule named JNJ-26854165 was shown to bind the RING domain of MDM2 and prevent the interaction of the MDM2-p53 complex with the proteasome. This molecule has been put on phase I clinical trial for advanced solid tumors [88, 89]. Various others small molecule inhibitors of E3 ubiquitin ligase activity of MDM2 as well as the MDM2-p53 interaction have been revealed later and are currently under pre-clinical development [50]. More interestingly, some of naturally derived molecules have been shown to decrease MDM2 expression and activity in vitro and in vivo, hence, inhibit the p53-MDM2 interaction [90]. In addition to the direct inhibitors, indirectly interrupting the MDM2-p53 negative feedback loop, which prevents MDM2-mediated degradation of p53, are also been explored for the development of molecule-targeted therapy for cancers [50]. Moreover, several miRNA have been identified that suppress MDM2, hence, miRNAs have become a new but important component of the p53 signaling pathway through regulating the p53/MDM2 feedback loop [91].

\section{CONCLUSION}

In nutshell, it can be suggested that incorporating information of the inherited genetic polymorphisms of the p53 pathway along with the somatic mutations in p53, patient populations can be stratified and therapies could be better targeted. These data support a hypothesis that individuals could develop cancer that retains wild type $p 53$, but still have an attenuated p53 response because they may harbor genetic polymorphisms either in $p 53$ gene or in MDM2 gene or HPV infection. Thus, comprehensive analysis of all the mechanisms by which p53 response is attenuated in oral cancer, is very essential to improve our understanding of oral cancer pathogenesis. Further, this knowledge will aid in improving prognosis and treatment of oral cancer.

\section{REFERENCES}

1. Ferlay J, Soerjomataram I, Ervik M, et al. GLOBOCAN 2012 v1.0, Cancer Incidence and Mortality Worldwide: IARC Cancer Base No. 11 [Internet]. Lyon, France: IARC; 2013. Available from: http://globocan.iarc.fr, accessed on 19/11/2014.

2. Chocolatewala NM, Chaturvedi P. Role of human papilloma virus in the oral carcinogenesis: an Indian perspective. J Cancer Res Ther 2009; 5: 71-7.

3. Campisi G, Panzarella V, Giuliani M, et al. Human papillomavirus: its identity and controversial role in oral oncogenesis, premalignant and malignant lesions. Int $\mathrm{J}$ Oncol 2007; 30: 813-23.

4. Paterson IC, Eveson JW, Prime SS. Molecular changes in oral cancer may reflect aetiology and ethnic origin. Eur J Cancer B Oral Oncol 1996; 32B: 150-3. 
5. Chen SF, Yu FS, Chang YC, et al. Role of human papillomavirus infection in carcinogenesis of oral squamous cell carcinoma with evidences of prognostic association. J Oral Pathol Med 2012; 41: 9-15.

6. Leemans CR, Braakhuis BJ, Brakenhoff RH. The molecular biology of head and neck cancer. Nat Rev Cancer 2011; 11: 9-22.

7. Choi S, Myers JN. Molecular pathogenesis of oral squamous cell carcinoma: implications for therapy. J Dent Res 2008; 87: 14-32.

8. Partridge M, Costea DE, Huang X. The changing face of p53 in head and neck cancer. Int J Oral Maxillofac Surg 2007; 36: 1123-38.

9. Whibley C, Pharoah PD, Hollstein M. p53 polymorphisms: cancer implications. Nat Rev Cancer 2009; 9: 95-107.

10. Freed-Pastor WA, Prives C. Mutant p53: one name, many proteins. Genes Dev 2012; 26: 1268-86.

11. Alexandrova EM, Mirza SA, Xu S, et al. p53 loss-ofheterozygosity is a necessary prerequisite for mutant $\mathrm{p} 53$ stabilization and gain-of-function in vivo. Cell Death Dis 2017; 8: e2661.

12. Herrera JC, Isaza LF, Ramírez JL, et al. Detection of chromosome 17 aneuplody and TP53 gene deletion in a broad variety of solid tumors by dual-color fluorescence in situ hybridization (FISH). Biomedica 2010; 30: 390-400.

13. Yu H, Huang YJ, Liu Z, et al. Effects of MDM2 promoter polymorphisms and $\mathrm{p} 53$ codon 72 polymorphism on risk and age at onset of squamous cell carcinoma of the head and neck. Mol Carcinog 2011; 50: 697-706.

14. Tang Y, Zhao W, Chen Y, et al. Acetylation is indispensable for p53 activation. Cell 2008; 133: 612-26.

15. Suzuki K, Matsubara H. Recent advances in p53 research and cancer treatment. J Biomed Biotechnol 2011; 2011: 978312.

16. Muller PA, Vousden KH. Mutant p53 in cancer: new functions and therapeutic opportunities. Cancer Cell 2014; 25: $304-17$.

17. Royds JA, Iacopetta B. p53 and disease: when the guardian angel fails. Cell Death Differ 2006; 13: 1017-26.

18. Chitra G, Chandramouli A, Chanchal C. p53 mutations in head and neck squamous cell carcinoma. Int $\mathbf{J}$ Pharm Biomed Res 2010; 1: 117-21.

19. Petitjean $A$, Mathe $E$, Kato $S$, et al. Impact of mutant p53 functional properties on TP53 mutation patterns and tumor phenotype: lessons from recent developments in the IARC TP53 database. Hum Mutat 2007; 28: 622-9.

20. Hong B, van den Heuvel AP, Prabhu VV, et al. Targeting tumor suppressor $\mathrm{p} 53$ for cancer therapy: strategies, challenges and opportunities. Curr Drug Targets 2014; 15: 80-9.

21. Heinzel PA, Balaram P, Bernard HU. Mutations and polymorphisms in the p53, p21 and p16 genes in oral carcinomas of Indian betel quid chewers. Int J Cancer 1996; 68: 420-3.

22. Munirajan AK, Tutsumi-Ishii Y, Mohanprasad BK, et al. p53 gene mutations in oral carcinomas from India. Int J Cancer 1996; 66: 297-300.

23. Saranath D, Tandle AT, Teni TR, et al. p53 inactivation in chewing tobacco-induced oral cancers and leukoplakias from India. Oral Oncol 1999; 35: 242-50.

24. Ralhan R, Agarwal S, Nath N, et al. Correlation between $\mathrm{p} 53$ gene mutations and circulating antibodies in betel- and tobacco-consuming North Indian population. Oral Oncol 2001; 37: 243-50.

25. Patnaik S, Nayak BK, Das BR. Genetic alteration of p53 in oral tumors. In: AK Varma, ed. Oral Oncology, Vol. VI. New Delhi, India: Macmillan India Limited, 1999: 87-92.

26. Lazarus $P$, Stern J, Zwiebel N, et al. Relationship between p53 mutation incidence in oral cavity squamous cell carcinomas and patient tobacco use. Carcinogenesis 1996; 17: 733-9.

27. Sorensen DM, Lewark TM, Haney JL, et al. Absence of p53 mutations in squamous carcinomas of the tongue in nonsmoking and nondrinking patients younger than 40 years. Arch Otolaryngol Head Neck Surg 1997; 123: 503-6.

28. Chaves AC, Cherubini K, Herter N, et al. Characterization of p53 gene mutations in a Brazilian population with oral squamous cell carcinomas. Int J Oncol 2004; 24: 295-303.

29. Wong YK, Liu TY, Chang KW, et al. p53 alterations in betel quid- and tobacco-associated oral squamous cell carcinomas from Taiwan. J Oral Pathol Med 1998; 27: 243-8.

30. Thongsuksai $P$, Boonyaphiphat $P$, Sriplung $H$, et al. p53 mutations in betel-associated oral cancer from Thailand. Cancer Lett 2003; 201: 1-7.

31. Hsieh LL, Wang PF, Chen IH, et al. Characteristics of mutations in the p53 gene in oral squamous cell carcinoma associated with betel quid chewing and cigarette smoking in Taiwanese. Carcinogenesis 2001; 22: 1497-503.

32. Singh RD, Patel KR, Patel PS. p53 mutation spectrum and its role in prognosis of oral cancer patients: A study from Gujarat, West India. Mutat Res 2016; 783: 15-26.

33. Peltonen JK, Helppi HM, Pääkkö P, et al. p53 in head and neck cancer: functional consequences and environmental implications of TP53 mutations. Head Neck Oncol 2010; 2: 36.

34. Hrstka R, Coates PJ, Vojtesek B. Polymorphisms in p53 and the p53 pathway: roles in cancer susceptibility and response to treatment. J Cell Mol Med 2009; 13: 440-53.

35. Pietsch EC, Humbey O, Murphy ME. Polymorphisms in the p53 pathway. Oncogene 2006; 25: 1602-11.

36. Patel KR, Vajaria BN, Begum R, et al. Association between p53 gene variants and oral cancer susceptibility in population from Gujarat, West India. Asian Pac J Cancer Prev 2013; 14: 1093-100.

37. Gallì $\mathrm{P}$, Cadoni $\mathrm{G}$, Volante $\mathrm{M}$, et al. A case-control study on the combined effects of p53 and p 73 polymorphisms on head and neck cancer risk in an Italian population. BMC Cancer 2009; 9: 137.

38. Mitra S, Sikdar N, Misra C, et al. Risk assessment of p53 genotypes and haplotypes in tobacco-associated leukoplakia and oral cancer patients from eastern India. Int J Cancer 2005; 117: 786-93.

39. Felley-Bosco E, Weston A, Cawley HM, et al. Functional studies of a germ-line polymorphism at codon 47 within the p53 gene. Am J Hum Genet 1993; 53: 752-9.

40. Beckman G, Birgander R, Själander A, et al. Is 53 polymorphism maintained by natural selection? Hum Hered 1994; 44: 266-70.

41. Ozeki C, Sawai Y, Shibata T, et al. Cancer susceptibility polymorphism of $\mathrm{p} 53$ at codon 72 affects phosphorylation and degradation of p53 protein. J Biol Chem 2011; 286: 18251-60.

42. Storey A, Thomas M, Kalita A, et al. Role of a p53 polymorphism in the development of human papillomavirusassociated cancer. Nature 1998; 393: 229-34.

43. Hsieh LL, Huang TH, Chen IH, et al. p53 polymorphisms associated with mutations in and loss of heterozygosity of the $\mathrm{p} 53$ gene in male oral squamous cell carcinomas in Taiwan. Br J Cancer 2005; 92: 30-5.

44. Azzam GA, Frank AK, Hollstein M, et al. Tissuespecific apoptotic effects of the p53 codon 72 polymorphism in a mouse model. Cell Cycle 2011; 10: 1352-5.

45. Hu Z, Li C, Chen K, et al. Single nucleotide polymorphisms in selected apoptotic genes and BPDE-induced apoptotic capacity in apparently normal primary lymphocytes: a genotype-phenotype correlation analysis. J Cancer Epidemiol 2008; 2008: 147905. 
46. Schneider-Stock R, Mawrin C, Motsch C, et al. Retention of the arginine allele in codon 72 of the p53 gene correlates with poor apoptosis in head and neck cancer. Am J Pathol 2004; 164: 1233-41.

47. Francisco G, Menezes PR, Eluf-Neto J, et al. Arg72Pro TP53 polymorphism and cancer susceptibility: a comprehensive meta-analysis of 302 case-control studies. Int J Cancer 2011; 129: 920-30.

48. Jiang N, Pan J, Wang L, et al. No significant association between p53 codon $72 \mathrm{Arg} /$ Pro polymorphism and risk of oral cancer. Tumour Biol 2013; 34: 587-96.

49. Mandal RK, Yadav SS, Panda AK. No evidence of correlation between $\mathrm{p} 53$ codon $72 \mathrm{G}>\mathrm{C}$ gene polymorphism and cancer risk in Indian population: a meta-analysis. Tumour Biol 2014; 35: 8607-13.

50. Zhang Q, Zeng SX, Lu H. Targeting p53-MDM2MDMX loop for cancer therapy. Subcell Biochem 2014; 85: 281-319.

51. Shwe M, Chiguchi G, Yamada S, et al. P53 and MDM2 co-expression in tobacco and betel chewing-associated oral squamous cell carcinomas. J Med Dent Sci 2001; 48: 113-9.

52. Lim KP, Sharifah H, Lau SH, et al. Alterations of the p14ARF-p53-MDM2 pathway in oral squamous cell carcinoma: MDM2 overexpression is a common event. Oncol Rep 2005; 14: 963-8.

53. Sam KK, Gan CP, Yee PS, et al. Novel MDM2 splice variants identified from oral squamous cell carcinoma. Oral Oncol 2012; 48: 1128-35.

54. Bond GL, Hu W, Bond EE, et al. A single nucleotide polymorphism in the MDM2 promoter attenuates the $\mathrm{p} 53$ tumor suppressor pathway and accelerates tumor formation in humans. Cell 2004; 119: 591-602.

55. Hamid S, Yang YH, Peng KN, etal. MDM2 SNP309 does not confer an increased risk to oral squamous cell carcinoma but may modulate the age of disease onset. Oral Oncol 2009; 45: $496-500$.

56. Misra C, Majumder M, Bajaj S, et al. Polymorphisms at $\mathrm{p} 53, \mathrm{p} 73$, and MDM2 loci modulate the risk of tobacco associated leukoplakia and oral cancer. Mol Carcinog 2009; 48: $790-800$.

57. Zhuo X, Ye H, Li Q, et al. Is MDM2 SNP309 variation a risk factor for head and neck carcinoma? An updated metaanalysis based on 11,552 individuals. Medicine (Baltimore), 2016; 95: e2948.

58. Syrjänen S, Lamberg M, Pyrhönen S, et al. Morphological and immunohistochemical evidence suggesting human papillomavirus (HPV) involvement in oral squamous cell carcinogenesis. Int J Oral Surg 1983; 12: 418-24.

59. Korzeniewski N, Spardy N, Duensing A, et al. Genomic instability and cancer: lessons learned from human papillomaviruses. Cancer Lett 2011; 305: 113-22.

60. Termine N, Panzarella V, Falaschini S, et al. HPV in oral squamous cell carcinoma vs head and neck squamous cell carcinoma biopsies: a meta-analysis (1988-2007). Ann Oncol 2008; 19: 1681-90.

61. Isayeva T, Li Y, Maswahu D, et al. Human papillomavirus in non-oropharyngeal head and neck cancers: a systematic literature review. Head Neck Pathol 2012; 6: S104-20.

62. Kansy K, Thiele O, Freier K. The role of human papillomavirus in oral squamous cell carcinoma: myth and reality. Oral Maxillofac Surg 2014; 18: 165-72.

63. Bychkov VA, Nikitina EG, Ibragimova MK, et al. Comprehensive meta-analytical summary on human papillomavirus association with head and neck cancer. Exp Oncol 2016; 38: 68-72.
64. El-Mofty SK, Lu DW. Prevalence of human papillomavirus type 16 DNA in squamous cell carcinoma of the palatine tonsil, and not the oral cavity, in young patients: a distinct clinicopathologic and molecular disease entity. Am J Surg Pathol 2003; 27: 1463-70.

65. Ribeiro KB, Levi JE, Pawlita M, et al. Low human papillomavirus prevalence in head and neck cancer: results from two large case-control studies in high-incidence regions. Int J Epidemiol 2011; 40: 489-502.

66. de Spíndula-Filho JV, da Cruz AD, Oton-Leite AF, et al. Oral squamous cell carcinoma versus oral verrucous carcinoma: an approach to cellular proliferation and negative relation to human papillomavirus (HPV). Tumour Biol 2011; 32: 409-16.

67. Akhter M, Ali L, Hassan Z, et al. Association of human papilloma virus infection and oral squamous cell carcinoma in Bangladesh. J Health Popul Nutr 2013; 31: 65-9.

68. Choi S, Myers JN. Molecular pathogenesis of oral squamous cell carcinoma: implications for therapy. J Dent Res 2008; 87: 14-32.

69. Patel KR, Vajaria BN, Begum R, et al. Prevalence of high-risk human papillomavirus type 16 and 18 in oral and cervical cancers in population from Gujarat, West India. J Oral Pathol Med 2014; 43: 293-7.

70. Yamazaki Y, Chiba I, Hirai A, et al. Radioresistance in oral squamous cell carcinoma with p53 DNA contact mutation. Am J Clin Oncol 2003; 26: e124-9.

71. Hassan NM, Tada M, Hamada J, et al. Presence of dominant negative mutation of TP53 is a risk of early recurrence in oral cancer. Cancer Lett 2008; 270: 108-19.

72. Tsurusako S, Tanaka H, Hayashi Y, et al. Low incidence of p53 mutations in well-differentiated tongue squamous cell carcinoma in Japan. Jpn J Clin Oncol 2002; 32: 327-31.

73. Sano D, Xie TX, Ow TJ, et al. Disruptive TP53 mutation is associated with aggressive disease characteristics in an orthotopic murine model of oral tongue cancer. Clin Cancer Res 2011; 17: 6658-70.

74. Tandon S, Tudur-Smith C, Riley RD, et al. A systematic review of $\mathrm{p} 53$ as a prognostic factor of survival in squamous cell carcinoma of the four main anatomical subsites of the head and neck. Cancer Epidemiol Biomarkers Prev 2010; 19: $574-87$.

75. Huang SF, Chen IH, Liao CT, et al. Combined effects of MDM2 SNP 309 and p53 mutation on oral squamous cell carcinomas associated with areca quid chewing. Oral Oncol 2009; 45: 16-22.

76. Dai M, Clifford GM, le Calvez F, et al. Human papillomavirus type 16 and TP53 mutation in oral cancer: matched analysis of the IARC multicenter study. Cancer Res 2004; 64: $468-71$.

77. Kozomara RJ, Brankovic-Magic MV, Jovic NR, et al. Prognostic significance of TP53 mutations in oral squamous cell carcinoma with human papilloma virus infection. Int J Biol Markers 2007; 22: 252-7.

78. O'Rorke MA, Ellison MV, Murray LJ, et al. Human papillomavirus related head and neck cancer survival: a systematic review and meta-analysis. Oral Oncol 2012; 48: 1191-201.

79. Vazquez A, Bond EE, Levine AJ, et al. The genetics of the p53 pathway, apoptosis and cancer therapy. Nat Rev Drug Discov 2008; 7: 979-87.

80. Yamazaki Y, Chiba I, Hirai A, et al. Specific p53 mutations predict poor prognosis in oral squamous cell carcinoma. Oral Oncol 2003; 39: 163-9.

81. Yasumoto J, Imai Y, Takahashi A, et al. Analysis of apoptosis-related gene expression after X-ray irradiation 
in human tongue squamous cell carcinoma cells harboring wild-type or mutated p53 gene. J Radiat Res 2003; 44: 41-5.

82. Tu HF, Chen HW, Kao SY, et al. MDM2 SNP 309 and p53 codon 72 polymorphisms are associated with the outcome of oral carcinoma patients receiving postoperative irradiation. Radiother Oncol 2008; 87: 243-52.

83. Perrone F, Bossi P, Cortelazzi B, et al. TP53 mutations and pathologic complete response to neoadjuvant cisplatin and fluorouracil chemotherapy in resected oral cavity squamous cell carcinoma. J Clin Oncol 2010; 28: 761-6.

84. Vekris A, Meynard D, Haaz MC, et al. Molecular determinants of the cytotoxicity of platinum compounds: the contribution of in silico research. Cancer Res 2004; 64: 356-62.

85. Wang D, Lippard SJ. Cellular processing of platinum anticancer drugs. Nat Rev Drug Discov 2005; 4: 307-20.

86. Vikhanskaya F, Siddique MM, Kei Lee M, et al. Evaluation of the combined effect of p53 codon 72 polymorphism and hotspot mutations in response to anticancer drugs. Clin Cancer Res 2005; 11: 4348-56.

87. Vivenza D, Gasco M, Monteverde M, et al. MDM2 309 polymorphism predicts outcome in platinumtreated locally advanced head and neck cancer. Oral Oncol 2012; 48: 602-7.

88. Kojima K, Burks JK, Arts J, et al. The novel tryptamine derivative JNJ-26854165 induces wild-type p53- and E2F1mediated apoptosis in acute myeloid and lymphoid leukemias. Mol Cancer Ther 2010; 9: 2545-57.

89. Yang Y, Ludwig RL, Jensen JP, et al. Small molecule inhibitors of HDM2 ubiquitin ligase activity stabilize and activate p53 in cells. Cancer Cell 2005; 7: 547-59.

90. Qin JJ, Nag S, Voruganti S, et al. Natural product MDM2 inhibitors: anticancer activity and mechanisms of action. Curr Med Chem 2012; 19: 5705-25. 